\section{Drying Interferes with Germination of Blackberry (Rubus sp.) Seeds in Vitro}

\author{
M.A.R. Mian ${ }^{1}$ \\ Department of Agronomy, University of Illinois, Turner Hall, Urbana, \\ IL 61801

\section{R.M. Skirvin ${ }^{2}$, M.A. Norton ${ }^{3}$, and A.G. Otterbacher ${ }^{4}$ \\ Department of Horticulture, University of Illinois, 258 Plant and Animal Biotechnology Laboratory, 1201 Gregory Drive, Urbana, IL 61801}

Additional index words. embryo culture, embryo rescue, tissue culture, Rubus laciniatus, fruit breeding, recalcitrant seed

\begin{abstract}
To study the causes of low germinability in dried blackberry seeds, seeds harvested from fresh 'Thornless Evergreen' (TE) blackberry (Rubus laciniatus Willd.) were either air-dried $(12,24,36,48,60,72,96$, or 120 hours) or explanted directly onto growth-regulator-free medium after bleach disinfestation. Seeds were either cut in half before explanting or kept intact. None of the intact seeds germinated. Fewer of the halved seeds dried 12 hours or more germinated than control (fresh moist) seeds $(42.7 \%$ and $54.5 \%$, respectively). Germination decreased to $<12 \%$ following $>48$ hours of air-drying. In a separate study, fresh seeds of TE and 'Navaho' were either dried as described or held in sealed petri dishes on moist filter paper (moist treatment) for up to 60 hours. After 60 hours, germination of dried seeds of both cultivars had decreased significantly; there was no significant change in germination percentage for moist seeds. Since moist halved seeds germinated well and dried halved seeds did not, the inability of dried blackberry seeds to germinate is due to more factors than just the hard seedcoat typical of the genus.
\end{abstract}

Bramble (Rubus sp.) seeds often germinate at low rates due to seed dormancy (Brinkmann, 1974). The percentage of germination can be improved by scarification procedures that remove or damage the hard seedcoat that surrounds the embryo, thus facilitating the entrance of water and $\mathrm{O}_{2}$ to initiate the biochemical processes associated with germination. After scarification, the seeds are stratified for 12 to 16 weeks under cool and moist conditions. These steps increase germination rates but reduce plant breeding efficiency by increasing the period between sexual generations and reducing the likelihood of obtaining a complete sampling of genotypes in hybrid progeny. Germination rates in brambles have been increased by use of improved scarification techniques (Campbell et al., 1988; Lundergan and Carlisi, 1984; Moore et al., 1974) as well as in vitro protocols (Ke et al.,

Received for publication 4 Feb. 1994. Accepted for publication 13 Oct. 1994. Funds for this research were provided in part by the Illinois Agricultural Experiment Station. Special thanks to Gene Galletta and Adam Dale for their encouragement in this research. The cost of publishing this paper was defrayed in part by the payment of page charges. Under postal regulations, this paper therefore must be hereby marked advertisement solely to indicate this fact.

${ }^{1}$ Postdoctoral Research Associate, Dept. of Crop and Soil Sciences, Univ. of Georgia, Athens, GA 30602.

${ }^{2}$ Professor of Horticulture; to whom reprint requests should be addressed.

${ }^{3}$ Postdoctoral Researcher, Dept. of Horticulture, Louisiana State Univ., Baton Rouge, LA 70803.

${ }^{4}$ Principal Research Specialist in Horticulture.
1985). In spite of these studies, the cause(s) of seeds are not well understood. Dale and Jarvis (1983) showed that freshly harvested raspberry ( $R$. idaeus L.) seeds germinated readily, but when they were dried, germination rates were reduced. We have made similar observations (Ke et al., 1985) with blackberries. This study was initiated to investigate the change in germinability between freshly harvested (moist) and dried blackberry seeds, with the goal of determining whether dormancy had been imposed during the drying period.

\section{Materials and Methods}

Drying interval (Expt. 1). Ripe fruits from 'Thornless Evergreen' (TE) blackberry were collected and the seeds separated from their pulp using a Braun hand blender. Although the "seed" of a blackberry includes a hard endocarp and its included true seed (Brinkmann, 1974), the term "seed" is commonly used to describe the entire structure. All immature and obviously defective seeds were discarded. The remaining seeds were divided into eight lots and either placed directly onto water agar medium (control) containing $7.5 \mathrm{~g}$ agar/liter (Sigma, St. Louis) in $15 \times 150$-mm plastic petri plates or dried for various intervals from 12 to $96 \mathrm{~h}$ on paper towels in an open petri dish at room conditions ( 22 to $24 \mathrm{C}, 50 \%$ to $60 \%$ relative humidity). Just before explanting, each seed lot was disinfected in $20 \%$ bleach solution $(1.5 \% \mathrm{NaOCl})$ with $0.1 \%$ Triton $\mathrm{X}-100$ added as a surfactant for $10 \mathrm{~min}$. The seeds were rinsed four to five times with sterile distilled water ( 2 min per rinse). Each seed (including the control) was then cut in half by low germinability of fresh dried blackberry a transverse cut perpendicular to the embryonic axis; both halves were placed on the petri plates using the procedures described by Ke et al. (1985). A total of 10 seeds ( 20 halves) was placed on medium at each time. There were 10 replications (10 petri dishes) for each treatment. In addition, five replications of 10 intact seeds also were used as a whole-seed control. All seeds were germinated in a culture room maintained under 16-h days (cool-white fluorescent light) between 20 and $22 \mathrm{C}$. The photosynthetically active radiation at the level of the agar surface was $131 \mu \mathrm{mol} \cdot \mathrm{m}^{-2} \cdot \mathrm{s}^{-1}$. The petri dishes were arranged in the culture room in a completely randomized design.

The number of germinated seeds in each petri dish was counted after 3 weeks of incubation; germination percentages were calculated. Data were analyzed by regression analysis procedures of SAS (SAS Institute, 1985). No germination was observed in the whole-seed control treatments; they were not included in the analyses.

Drying interval and seed moisture content $(S M C)$. This experiment was conducted using the same procedures described in the first experiment except for the following: 1) drying times were $0,12,24,48,72,96$, and $120 \mathrm{~h}$, and 2) SMC was determined by weighing 200 seeds at the end of each drying period $\left(\mathrm{FW}_{\mathrm{i}}\right)$. The 200 seeds were then oven-dried at $68 \mathrm{C}$ for 14 days and weighed again $\left(\mathrm{DW}_{\mathrm{i}}\right)$. The percentage of SMC was calculated as $\left[\left(\mathrm{FW}_{\mathrm{i}}-\right.\right.$ $\left.\left.\mathrm{DW}_{\mathrm{i}}\right) / \mathrm{FW}_{\mathrm{i}}\right] \times 100$, where $\mathrm{i}$ stands for the $\mathrm{i}^{\text {th }}$ drying period.

Moisture maintenance (Expt. 3). In this experiment, ripe fruit were collected from both TE and 'Navaho' blackberries and prepared as described in the first experiment. However, in this experiment, the seeds were divided into two lots: the seeds of one lot were kept moist in a sealed petri dish and never allowed to dry, while the seeds of the other lot were air-dried at room temperature as described earlier. Seeds were disinfected, cut in half, and placed on germination medium 0,12 , $24,36,48$, and $60 \mathrm{~h}$ after cleaning them free of their pulpy flesh. Five replications (petri plates) with 10 seeds per petri plate were used for each treatment and cultivar in this experiment.

\section{Results and Discussion}

None of the intact seeds germinated in these experiments, regardless of the drying interval (data not presented). In all three experiments, fresh (nondried) halved seeds germinated best, followed by seeds dried for $12 \mathrm{~h}$ (Figs. 1-3). The regression analyses between drying interval and germination percentages was significant for all three experiments (Expt. 1: $r^{2}=0.949$; Expt. 2: $r^{2}=0.960$; Expt. 3: $r^{2}(\mathrm{TE})=0.979, r^{2}$ ('Navaho') $=0.989$ ). In all three experiments, a sharp decline in germination occurred during the first $48 \mathrm{~h}$ of drying; the decline was less pronounced during the 48- to 120-h interval. For instance, in the first two experiments, less than $12 \%$ of seeds dried $48 \mathrm{~h}$ or more germinated (Fig. 1). The effect of drying $48 \mathrm{~h}$ was less pronounced in Expt. 3 (19\% and 41.6\% germination for TE 


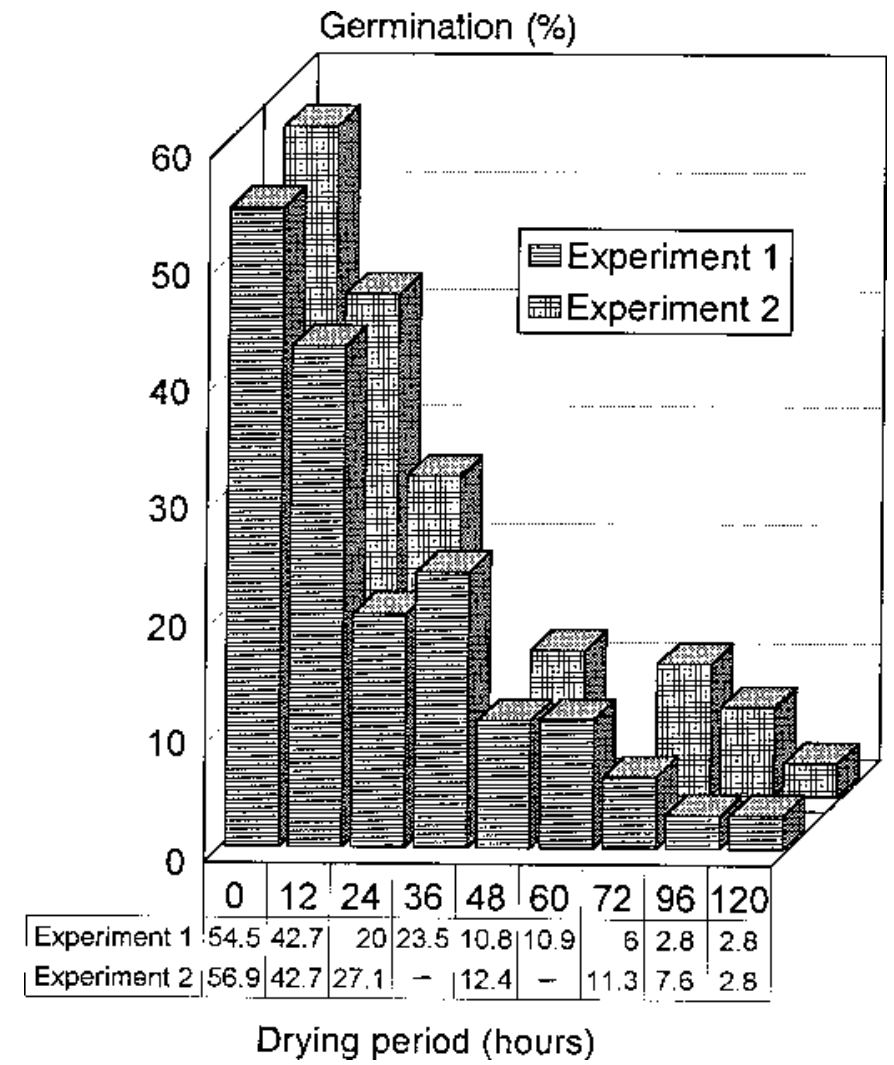

Fig. 1. The effect of drying interval on germination of halved 'Thornless Evergreen' blackberry seeds in vitro (Expts. 1 and $2 ; \mathrm{n}=100)$. Experiment 1: $\mathrm{y}=51.93-1.07 \mathrm{x}+0.0056 \mathrm{x}^{2}, r^{2}=0.949 ;$ Expt. $2: \mathrm{y}=53.67-$ $1.03 \mathrm{x}+0.053 \mathrm{x}^{2}, r^{2}=0.960$.

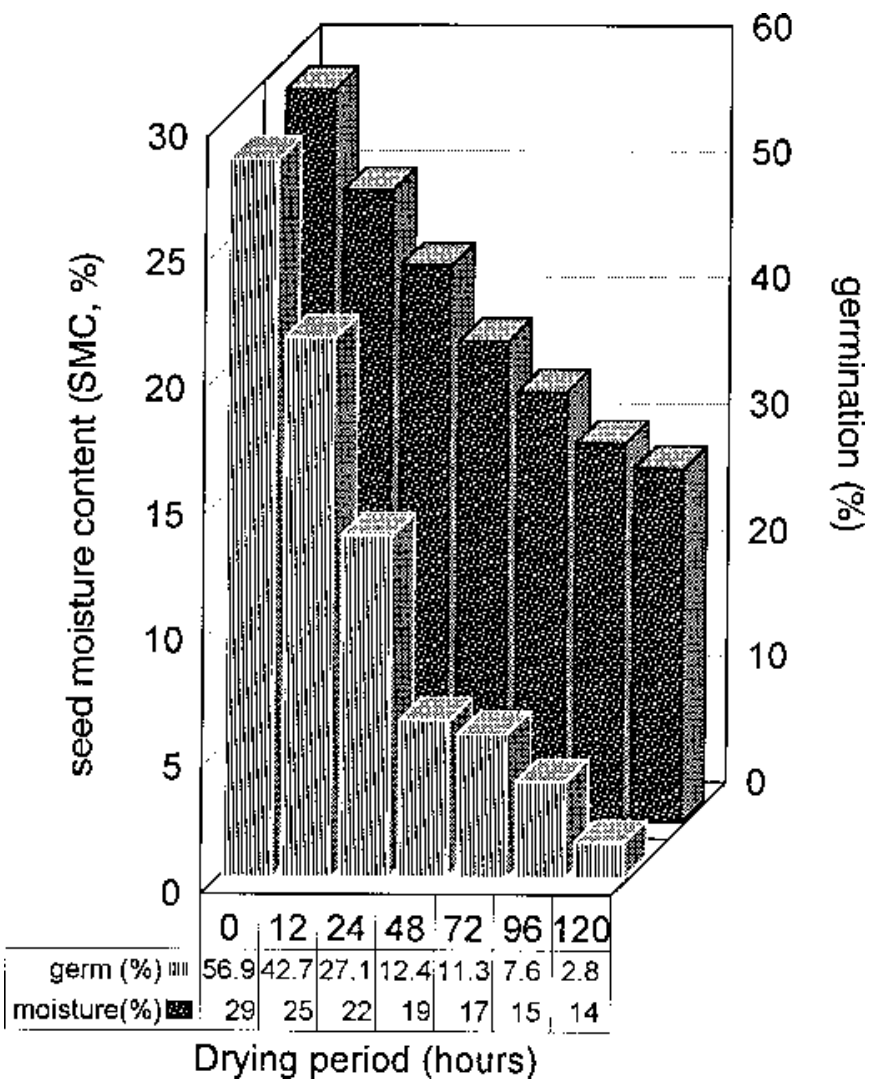

Fig. 2. The effect of drying interval and seed moisture content (SMC) on germination of halved 'Thornless Evergreen' blackberry seeds in vitro (Expt. $2: \mathrm{n}=100 ; \mathrm{y}=-50.06+3.626 \mathrm{x} ; r^{2}=0.97$ ). and 'Navaho', respectively), but the trends were similar.

In the second experiment, a highly significant linear relationship $\left(r^{2}=0.97\right)$ existed between SMC and seed germination expressed by the equation $\%$ germination $=-50.06+$ 3.626 (SMC) (Fig. 2). The fresh half seeds with the highest SMC (29\%) had the highest germination. Germination rates declined rapidly as SMC decreased, and few seeds germinated at or below a SMC value of $19 \%$. The relationship between SMC and germination percentage in the present study closely resembles that of a recalcitrant seed (Chin, 1988). Roberts (1973) stated that a decrease in moisture content of recalcitrant seeds below some relatively high value, anything between $12 \%$ to $31 \%$ moisture content, depending on the species, tends to decrease viability; whereas for calcitrant (orthodox) seeds, the period of viability may be extended by lowering their moisture content during storage. In such seeds, the moisture content may be reduced to $2 \%$ to $5 \%$, or even lower, before further drying ceases to increase the viability period (Roberts, 1959).

Our results indicate that at least two factors contribute to the failure of dried bramble seeds to germinate. 1) The seed covering (seedcoat and endocarp) of blackberry and raspberry forms a physical barrier for seed germination that prevents germination in vitro. Ke et al. (1985) showed that this barrier could be overcome by cutting the seed in half and germinating the seed halves in vitro. 2) The act of drying may decrease the viability of blackberry seeds if they belong to the recalcitrant group of seeds. Drying also may induce dormancy in the seed, possibly by increasing endogenous levels of a germination inhibitor, such as abscisic acid (ABA), in the embryo that migrated from the seedcoat or outer layers of the cotyledon, where it resided in the moist seeds, deeper in the embryo. We do not know of any documented case of this kind of growth inhibitor migration. Bewley and Black (1985) reported that amputation of cotyledons often allows the embryonic axis of dormant embryos to germinate and grow. For instance, dormancy was partially or completely broken in hazelnut (Corylus avellana L.; Jarvis, 1975), and spindle tree (Euonymous europaea L.; Bulard and Monin, 1960) by excising one cotyledon, and in ash (Fraxinus excelsior L.; Bulard and Monin, 1963) by cutting off two cotyledons. The degree of dormancy in apple (Malus domestica Borkh.) cotyledons appears to be a function of the amount of cotyledon tissue left attached (Thevenot and Come, 1973). Bewley and Black (1985) suggest that such an inhibitory effect of cotyledons on germination is exerted through a chemical, possibly ABA. It is also possible that drying stimulated the synthesis of inhibitor(s).

To determine whether moist seeds retained their ability to germinate normally over the period of our experiment, Expt. 3 was designed. In the case of moist seeds, germination remained almost constant throughout the period of the experiment for either genotype (Fig. 3). For the dried seed, both genotypes showed significant reductions in germination 


\section{germination (\%)}

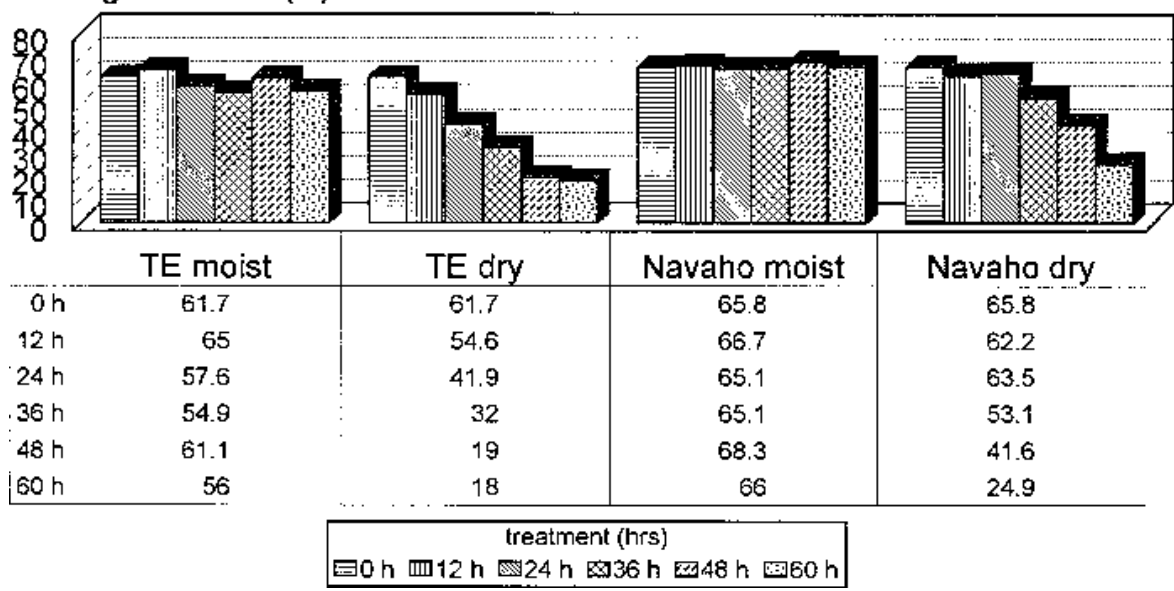

Fig. 3. The effect of moisture maintenance on germination of halved blackberry seeds in vitro (Expt. 3, $\mathrm{n}=50$ ). 'Thornless Evergreen' $(\mathrm{TE})$ : moist $=$ nonsignificant $(\mathrm{NS})$, dry $=63.55-1.02 \mathrm{x}+0.0036 \mathrm{x}^{2}, r^{2}=$ 0.979; 'Navaho': moist $=$ Ns, dry $=64.67+0.21-0.0145 x^{2}, r^{2}=0.989$.

rates over the 60 -h interval. These results are similar to those of Dale and Jarvis (1983) and support our hypothesis that the induction of dormancy in blackberry is related to a dormancy-inducing factor that is not present in the embryo at harvest, but enters and has its dormancy-inducing effects as the seed dries. The other hypothesis is that the seeds failed to germinate after drying because they were dead due to their recalcitrant nature. Further studies will be needed to confirm or discard either of these hypotheses.

\section{Literature Cited}

Bewley, J.D. and M. Black. 1985. Seeds, physiology of development and germination. Plenum Press, New York. p. 179-180.

Brinkmann, K.A. 1974. Rubus L. blackberry, raspberry, p. 738-743. In: C.S. Schopmeyer (ed.). Seeds of woody plants in the United States. U.S. Dept. Agr. Hbk. 450.

Bulard, C. and J. Monin. 1960. Action de l'acide gibberellique sur des embryons dormants d'Euonymous europaeus cultives in vitro. Comptes Rendus Acad. Sci. 250:2922-2924.
Bulard, C. and J. Monin. 1963. Etude du comportement d'embryons de Fraxinus excelsior L. preleves dans des graines dormantes et cultives in vitro. Phyton (Buenos Aires) 20:115125.

Campbell, P.L., D.J. Erasmus, and J. van Staden. 1988. Enhancing seed germination of sand blackberry. HortScience 23:560-561.

Chin, H.F. 1988. Recalcitrant seeds, a status report. Intl. Board Plant Genet. Resources.

Dale, A. and B.C. Jarvis. 1983. Studies on germination in raspberry (Rubus idaeus L.). Crop Res. 23:73-81.

Jarvis, B.C. 1975. The role of seed parts in the induction of dormancy in hazel (Corylus avellana L). New Phytol. 75:491-494.

Ke, S., R.M. Skirvin, K.D. McPheeters, A.G. Otterbacher, and G. Galletta. 1985. In vitro germination and growth of Rubus seeds and embryos. HortScience 20:1047-1049.

Lundergan, C.A. and J.A. Carlisi. 1984. Acceleration of the reproductive cycle of the cultivated blackberry. HortScience 19:102-103.

Moore, J.N., G.R. Brown, and C.A. Lundergan. 1974. Effect of duration of scarification on endocarp thickness and seedling emergence of blackberries. HortScience 9:204-205.

Roberts, E.H. 1959. The effect of storage conditions on the viability of grass seeds. Proc. Intl. Seed Testing Assn. 24:184-213.

Roberts, E.H. 1973. Predicting the storage life of seeds. Seed Sci. Technol. 1:499-503.

SAS Institute. 1985. SAS user's guide: Statistics. SAS Inst., Cary, N.C.

Thevenot, C. and D. Come. 1973. Inhibition de la germination de l'axe embryonaire par les cotyledons chez pommier (Pirus malus L.). Comptes Rendus Acad. Sci. Ser. D 277:1873-1876. 